Investigación original / Original research

\title{
Measuring and explaining health and health care inequalities in Jamaica, 2004 and 2007
}

\author{
Ewan Scott ${ }^{1}$ and Karl Theodore ${ }^{1}$
}

Suggested citation Scott E, Theodore K. Measuring and explaining health and health care inequalities in Jamaica, 2004 and 2007. Rev Panam Salud Publica. 2013;33(2):116-21.

ABSTRACT Objective. This study addresses the need to measure and explain the inequalities and inequities of Jamaica's health system to generate evidence to support policy development, monitoring, and evaluation.

Methods. The nationally representative Jamaica Survey of Living Conditions data sets for 2004 and 2007 were used to produce concentration curves and concentration indices for three health outcome variables (probability of any illness or injury, duration of latest episode of illness, and self-assessed health status) and two health care utilization variables (probability of a curative visit to a health practitioner and number of curative visits) to measure income-related inequalities. Their standardized counterparts were used to measure inequities. Decomposition of the concentration index provides a basis for explaining the contributions of socioeconomic and demographic factors to overall inequalities.

Results. Probability of illness and duration of illness were concentrated among the poor, while there was a distinct pro-rich inequality with respect to utilization of heath care services. These inequalities and inequities became more pronounced over the period 2004-2007. The level of household welfare was found to be the single most significant factor contributing to these inequalities. Other significant contributing factors were unemployment and rural location for health outcomes and insurance coverage for utilization of services.

Conclusions. In spite of measures taken ostensibly to address health equity in Jamaica, income-related inequalities in health outcomes and health care have increased and the population group that needs health services most is using them least. These findings suggest a need for more innovative programs geared toward improving equity in health in Jamaica.

Key words Equity in health; equity in access; health systems; health economics; health policy; Jamaica.

Like many countries in Latin America and the Caribbean (LAC), Jamaica continues to grapple with improving the performance of its health system in the context of anemic economic growth over the past decade. Jamaica's gross domestic product per capita was US\$ 9000 in

\footnotetext{
${ }^{1}$ University of the West Indies, Centre for Health Economics, St. Augustine, Trinidad and Tobago. Send correspondence to: Ewan Scott, ewan.scott@sta.uwi.edu
}

2011 and it is ranked as a middle-income country. Private health expenditure accounted for a little less than half of total spending on health in Jamaica. The country has no mandatory health insurance schemes, and private insurance coverage, which is largely employer based, increased from $18.4 \%$ to $21.2 \%$ over the period 2004-2007. The public health system is the main provider of health care services to the lower-income population and governments have com- mitted to policies and programs aimed at improving the health status of the poor and ensuring more equitable access to health care services.

At the heart of these efforts is the principle of horizontal equity-that is, equal treatment for equal need. This principle has led to initiatives such as Jamaica's Drugs for the Elderly Program in 1996, the National Health Fund in 2003, and, in 2008, the removal of user fees at public health facilities (1-3), all aimed at reduc- 
ing the financial burden of health care to the public and enhancing access to services. These initiatives have had mixed results, and not all stakeholders were entirely happy with their implementation and unintended consequences (4-6). The National Health Fund-which subsidizes the cost of treatment for a range of illnesses including asthma, diabetes, breast cancer, hypertension, arthritis, and glaucoma in addition to providing funding for equipment and improvement in the health infrastructure $(1,2)$ is partially financed by the National Insurance Scheme. However, labor unions were critical of the adjustment to wage deductions effected by the National Insurance Scheme (4). The removal of user fees also saw stakeholders in the health sector such as the Medical Association of Jamaica and the Nurses Association lamenting the strain on resources that resulted $(5,6)$. Given the political tension surrounding establishment of these policies, there would be value added in creating clear criteria for measuring whether they are deemed successful as well as a sustained effort to measure progress over time. In light of the principles underlying these programs, assessing whether inequalities and inequities in health are narrowing in Jamaica would provide a reasonable measure of the success of these policies. Inequality is assessed via the income-related distribution of actual health outcomes and health care utilization, while horizontal inequity is assessed via standardized distributions. Health outcomes are standardized by age and sex, while health care utilization is standardized for need as well as age and sex. Previous studies of the Jamaican health system, using data from the early 1990s, investigated such inequalities and inequities $(7,8)$. These studies found patterns of a propoor inequity in illness but a pro-rich inequity in health care utilization. Other studies of the wider LAC region found similar patterns $(9,10)$; this paradox is pervasive in developed and developing countries alike and persistent despite substantial state support to address the issue (11-13).

The aim of this study is to derive measures of health inequities in order to provide evidence as to whether this circumstance has improved or persisted over time in Jamaica and to explain these measures by investigating and assessing the possible contributing factors.
The results presented here are part of a wider study on health care inequalities in the Americas commissioned by the Pan American Health Organization.

\section{MATERIALS AND METHODS}

This study constitutes original observational research that applies analytic tools to secondary data. The concentration curve was used to depict the degree of inequities in the health variables; its numerical counterparts-the concentration index (CI) and the horizontal inequity index (HI) - were used to measure the magnitude of inequalities and inequities. Decomposition of the CI is used to determine the relative contributions of various factors to the extent of the existing equalities. Use of the concentration curve and the CI has become standard methodology in the literature on health equity $(14,15)$. A detailed description of these tools and their application to the country studies is provided in the article by Almeida et al. (16).

With data from the Jamaica Survey of Living Conditions (JSLC), 2004 and 2007 data sets (17), these methods were applied to three health status and outcome variables and two health care utilization variables: the probability of any illness or injury, duration of the latest episode of illness, probability of less than good self-assessed health, probability of any curative visit to a health professional, and number of such curative visits. Table 1 provides a description of these variables. The recall period for the health module of the JSLC is four weeks.

The JSLC is nationally representative of noninstitution dwellings and collects household and individual data from a random subset of approximately onethird of the sample of dwellings covered by the Labour Force Survey (18). The sampling design of the Labour Force Survey is that of a two-stage stratified random sample designed to select approximately $1.5 \%$ of all dwellings in Jamaica (19). The JSLC collects information on consumption, health, education, nutrition, housing, demographic characteristics, and the food stamp program. The main purpose of the survey is to provide the government with information for policy development and planning. The JSLC is similar to the World Bank's Living Standards Measurement Study household surveys, but it has a narrower focus, allowing for greater emphasis on policy impact (18).

The 2004 and 2007 data sets contain information on almost 2000 households, and the analysis is based on the sample of individuals 18 years or older. The analysis for health care utilization was done for those individuals who reported an injury or illness over the reference period. Health outcomes were standardized by age and sex groups; for health care utilization, categorical variables were added for self-assessed health, the presence and degree of any physical limitation, and the presence of any chronic illness as proxies for need. The living standard (income) measure used was household consumption expenditure per adult equivalent. Controls (nonstandardizing variables) included dummy variables for education, economic activity status, rural residence, marital status, private insurance coverage, and household size. Table 2 gives the mean values for these variables for the two data sets.

\section{TABLE 1. Description of analysis variables}

\begin{tabular}{|c|c|}
\hline Variable & Description ${ }^{a}$ \\
\hline \multicolumn{2}{|l|}{ Health status } \\
\hline Self-assessed health ${ }^{b}$ & $\begin{array}{l}\text { Categorical: "How do you describe your general health status?" Very good, } \\
\text { good, fair, poor, and very poor. }\end{array}$ \\
\hline Injured or ill & $\begin{array}{l}\text { Categorical: Combination of "have you had any injury resulting from ... that } \\
\text { required medical attention?" and "have you had any illnesses other than } \\
\text { injury?" Yes or no. }\end{array}$ \\
\hline Duration of illness (days) & Numeric count: "How long did this last episode of illness last?" \\
\hline \multicolumn{2}{|l|}{ Health care utilization } \\
\hline $\begin{array}{l}\text { Curative visit to health } \\
\text { practitioner }\end{array}$ & $\begin{array}{l}\text { Categorical: "Has a doctor, nurse, pharmacist, midwife, healer or any other } \\
\text { health practitioner been visited?" Yes or no. }\end{array}$ \\
\hline Number of curative visits & Numeric count: "How many visits did you make to health practitioners?" \\
\hline
\end{tabular}




\section{RESULTS}

Findings for the five health variables are presented in three parts: comparisons by income quintiles, CI and HI values, and contributions to the CI.

The concentration curves for the standardized health variables indicate that

TABLE 2. Mean values of standardizing and control variables, Jamaica, 2004 and 2007

\begin{tabular}{|c|c|c|}
\hline \multirow[b]{2}{*}{ Standardizing variable } & \multicolumn{2}{|c|}{ Mean } \\
\hline & 2004 & 2007 \\
\hline \multicolumn{3}{|l|}{ Age (years) } \\
\hline $18-34$ & 0.411 & 0.395 \\
\hline $35-44$ & 0.213 & 0.215 \\
\hline $45-64$ & 0.231 & 0.246 \\
\hline $65-74$ & 0.081 & 0.078 \\
\hline$>75$ & 0.064 & 0.066 \\
\hline \multicolumn{3}{|l|}{ Sex } \\
\hline Male & 0.478 & 0.474 \\
\hline Female & 0.522 & 0.526 \\
\hline \multicolumn{3}{|l|}{ Health status } \\
\hline Very good & 0.409 & 0.325 \\
\hline Good & 0.367 & 0.444 \\
\hline Fair & 0.150 & 0.165 \\
\hline Poor & 0.060 & 0.055 \\
\hline Very poor & 0.013 & 0.011 \\
\hline \multicolumn{3}{|l|}{ Physical limitation } \\
\hline Moderate & 0.073 & 0.095 \\
\hline Severe & 0.009 & 0.010 \\
\hline Any chronic disease & 0.020 & 0.033 \\
\hline \multicolumn{3}{|l|}{ Education } \\
\hline Primary or lower & 0.174 & 0.140 \\
\hline Some secondary & 0.275 & 0.293 \\
\hline \multicolumn{3}{|l|}{ Activity status } \\
\hline Unemployed & $\ldots$ & 0.337 \\
\hline Self-employed & $\ldots$ & 0.235 \\
\hline Other (student) & 0.034 & 0.039 \\
\hline Private health insurance & 0.068 & 0.136 \\
\hline Rural residence & 0.504 & 0.468 \\
\hline Marital status & 0.436 & 0.426 \\
\hline Household size & 4.33 & 4.22 \\
\hline Living standarda & 148.3 & 240.2 \\
\hline
\end{tabular}

income-related inequities exist for all five variables according to the 2007 data (see supplementary material). All three health outcome variables exhibit propoor inequity; their curves lie above the line of equality, with duration of illness showing a greater degree of inequity than the probability of illness or selfassessed health. Conversely, the curves for the probability of a curative visit and the number of curative visits to a health practitioner lie below the line of equality-evidence of pro-rich inequity in the utilization of health care services in Jamaica. The curves for 2004 are close towith some crossing - the line of equality, suggesting that the degree of health inequities was small compared with 2007; that is, inequities have increased over the three-year period.

\section{Health and health care by income quintiles}

Table 3 shows that for all three health outcome variables and for both years, comparisons with the population mean reveal that the two poorest quintiles have incidences of ill health that are generally above the population average. This result means that, regardless of differences in age and sex, Jamaicans in lower-income categories are more likely to be injured or ill, are ill for longer, and are more likely to report their health to be less than good. The probability of reporting less than good health for the poorest income quintile is almost double that of the richest quintile in $2004-29.4 \%$ and $17.8 \%$, respectively, with only a small narrowing by 2007 . The average proportion of the population reporting an injury or illness increased from $12.7 \%$ in 2004 to $17.4 \%$ in
2007, but the increase was larger for the two poorest quintiles than for the rest of the population, resulting in evidence of a greater burden of illness on the poor over the three-year period. The duration of illness shows a somewhat similar pattern. The poorest quintile saw an increase in the mean length of time of illness from 1.5 days in 2004 to 2.2 days in 2007, while the richest quintile saw a decrease of 0.2 day, further evidence of an increased burden of ill health among the poor over the same period.

Table 3 also reveals that the distributions of the health care utilization variables differ from those for the health outcome variables. For both years, over $67.0 \%$ of those who reported an injury or illness made a curative visit to a health practitioner. In comparison, for 2004, this proportion is lower in both the poorest and the richest quintiles but ranges between $68.6 \%$ and $72.0 \%$ in the three middle quintiles. This pattern becomes decidedly pro-rich in 2007, rising from $54.1 \%$ to $63.3 \%$ in the two lower quintiles and from $76.5 \%$ to $80.2 \%$ in the two upper quintiles. This finding means that, given the same need, Jamaicans with higher incomes are more likely to make a curative visit to a health practitioner. The number of curative visits follows a similar pattern, suggesting that higherincome Jamaicans are not only more likely to seek health care but will also do so more frequently.

\section{Indices of inequality and inequity}

The nonstandardized CIs and the HIs for all five health variables are reported in Table 4. All the indices presented are statistically significant at the $5 \%$ level or

TABLE 3. Standardized quintile distributions of health and health care variables, Jamaica, 2004 and 2007

\begin{tabular}{|c|c|c|c|c|c|c|c|}
\hline Variable & Year & Mean & Poorest $20 \%$ & 2nd Poorest 20\% & Middle & 2nd Richest $20 \%$ & Richest $20 \%$ \\
\hline \multicolumn{8}{|l|}{ Health status } \\
\hline \multirow{2}{*}{$\begin{array}{l}\text { Less than good self-assessed } \\
\text { health }\end{array}$} & 2004 & 0.226 & 0.294 & 0.250 & 0.217 & 0.198 & 0.178 \\
\hline & 2007 & 0.230 & 0.299 & 0.228 & 0.225 & 0.210 & 0.185 \\
\hline \multirow[t]{2}{*}{ Any injury or illness } & 2004 & 0.127 & 0.139 & 0.129 & 0.111 & 0.126 & 0.132 \\
\hline & 2007 & 0.174 & 0.194 & 0.185 & 0.165 & 0.171 & 0.156 \\
\hline \multirow[t]{2}{*}{ Duration of illness (days) } & 2004 & 1.320 & 1.525 & 1.702 & 1.021 & 1.137 & 1.246 \\
\hline & 2007 & 1.393 & 2.219 & 1.341 & 1.246 & 1.106 & 1.051 \\
\hline \multicolumn{8}{|l|}{ Health care utilization } \\
\hline \multirow[t]{2}{*}{ Any curative visit } & 2004 & 0.673 & 0.622 & 0.693 & 0.720 & 0.686 & 0.656 \\
\hline & 2007 & 0.674 & 0.541 & 0.633 & 0.687 & 0.802 & 0.765 \\
\hline \multirow[t]{2}{*}{ Number of curative visits } & 2004 & 0.947 & 0.863 & 1.026 & 0.963 & 0.974 & 0.929 \\
\hline & 2007 & 0.964 & 0.619 & 0.865 & 1.116 & 1.196 & 1.167 \\
\hline
\end{tabular}


TABLE 4. Concentration indices for health status and health care utilization variables, Jamaica, 2004 and 2007

\begin{tabular}{|c|c|c|c|c|c|}
\hline \multirow[b]{2}{*}{ Variable } & \multicolumn{2}{|c|}{2004} & \multicolumn{2}{|c|}{2007} & \multirow{2}{*}{$\begin{array}{l}\text { HI difference } \\
\text { 2007-2004 }\end{array}$} \\
\hline & $\mathrm{Cl}$ & $\mathrm{HI}$ & $\mathrm{Cl}$ & $\mathrm{HI}$ & \\
\hline \multicolumn{6}{|l|}{ Health status } \\
\hline Less than good self-assessed health & $-0.129^{a}$ & $-0.103^{a}$ & $-0.130^{\mathrm{a}}$ & $-0.093^{a}$ & $0.010^{a}$ \\
\hline Any injury or illness & $-0.018^{a}$ & $-0.002^{\mathrm{a}}$ & $-0.075^{\mathrm{a}}$ & $-0.043^{a}$ & $-0.040^{\mathrm{a}}$ \\
\hline Duration of illness (days) & $-0.086^{a}$ & $-0.066^{a}$ & $-0.194^{a}$ & $-0.161^{\mathrm{a}}$ & $-0.094^{a}$ \\
\hline \multicolumn{6}{|l|}{ Health care utilization } \\
\hline Any curative visit & $-0.010^{\mathrm{a}}$ & $0.016^{a}$ & $0.059^{a}$ & $0.080^{a}$ & $0.064^{a}$ \\
\hline Number of curative visits & $-0.017^{a}$ & $0.019^{a}$ & $0.094^{a}$ & $0.121^{a}$ & $0.102^{\mathrm{a}}$ \\
\hline
\end{tabular}

$\mathrm{Cl}$ : concentration index, $\mathrm{HI}$ : horizontal inequity index.

a Significant at $P<0.05$.

higher. For the three health status variables, the negative signs indicate that the observed income-related inequality and that which remains after correcting for age and sex differences are pro-poor. While the differences in the HI from 2004 to 2007 are relatively small, they are statistically different from zero and the negative signs for "any injury or illness" and "duration of illness" show a noticeable increase in the pro-poor inequity in ill health over the three-year period.

The HI values for the two health care utilization variables give evidence of an increasingly pro-rich inequity in the use of health care in Jamaica between 2004 and 2007. In 2004, even though a marginally pro-poor inequality is observed for the probability and frequency of curative visits, when the distribution is based on equal need, a pro-rich inequity is revealed. The change in the HI for these two variables from 2004 to 2007 implies that the situation worsened over time. The HI for the number of visits in particular moved from 0.019 to 0.121 , a relatively large change of 0.102 for the three-year period.

\section{Sources of inequity}

Figure 1 charts the CI for the health care utilization variables analyzed for the two years and shows the relative magnitudes of the factors contributing to the composition of the index. For the probability and intensity of health care visits, the contribution of need (the sum of the contributions of the demographic and morbidity variables) is negative for both years. This result implies that access to health care based on need will ensure that the pro-rich inequality in health care use is lower than it would be if need were not a main determinant of health care use. The remaining inequalities after accounting for need are seen as unjustified and contribute to inequity in health care utilization.

Figure 1 also shows that the unequal distribution of income is the single most significant contributor to the inequities observed, contributing largely to the prorich distributions of health care utilization and to the increase in horizontal inequity from 2004 to 2007. A similar pattern is observed for health insurance coverage; it contributes strongly to the pro-rich inequity in health care utilization, more so in 2007 than in 2004. Rural residence is another notable contributor to inequities. The predominantly negative contribution of rural residence means that inequalities in the probability and number of curative visits are lower than they would be

FIGURE 1. Contributions to concentration index for health care utilization variables, Jamaica, 2004 and 2007

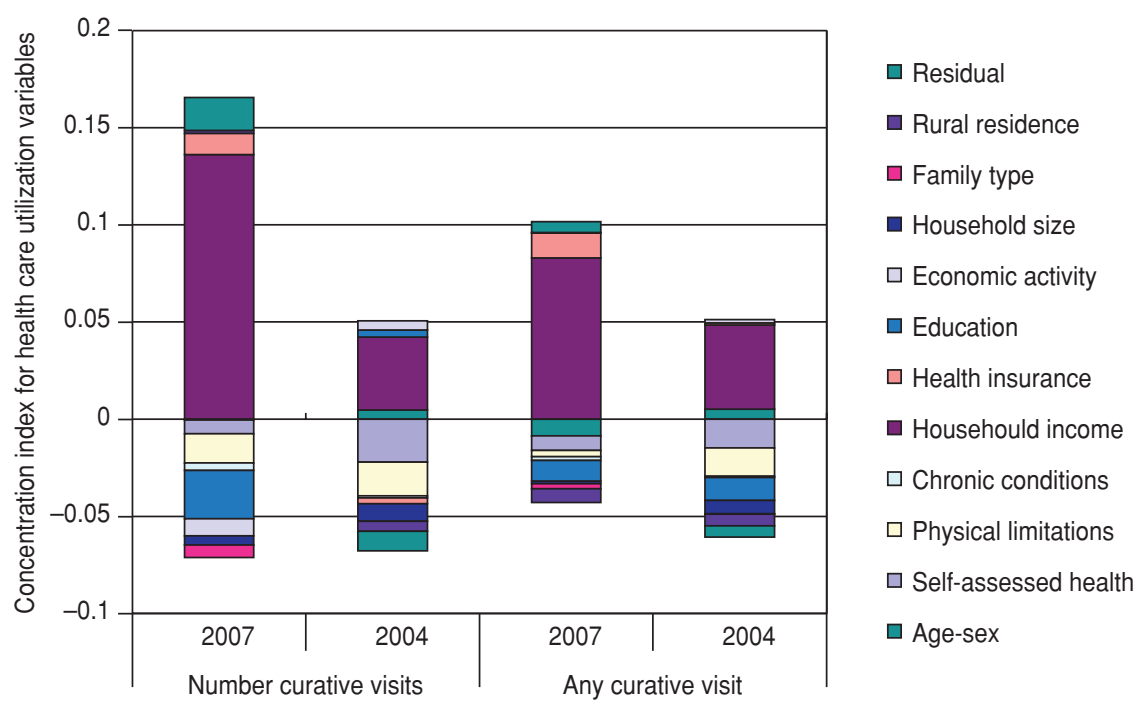

if there were no income differences and no utilization differences across rural and urban Jamaica. In other words, better access to health care in rural Jamaica would reduce pro-rich inequity in health care utilization. Economic activity other than formal employment (i.e., unemployed, self-employed, student) also contributed to the pro-rich inequality in health care utilization but less so in 2007. The decomposition also suggests that the contributions to inequity of other control variables such as household size and family type were negligible for both utilization variables.

\section{DISCUSSION}

This article describes the analysis of inequities in health outcomes and health care utilization in Jamaica using household survey data for the years 2004 and 2007. The analysis of health equity in Jamaica was positioned in the interesting context in which public health spending averaged just around $2.4 \%$ of gross domestic product over the period 2004-2007, with total health spending averaging $4.0 \%$ (20). These figures are low in an international context, which in the environment of income inequality that characterizes LAC should lead us to expect related inequalities in health. Studies at the turn of the century on health equity for countries of the LAC region as well as developed countries found evidence of such inequalities (9,

. 
11). More recent studies found that these inequities have persisted over time (13).

These findings corroborate results from earlier studies done for Jamaica $(7,8)$ but also shed some light on the sources of these inequities. The analysis found that the probability of illness and the duration of illness were concentrated among the poor, while there was a distinct pro-rich inequality with respect to utilization of heath care services. After standardization for demographics and need, the horizontal inequities that remain are still distinctive. These inequalities and inequities became more pronounced in the period 2004-2007, with the burden of illness shifting to the lowest-income groups, while access to health care became skewed toward the higher-income groups. For the year 2007, the measure of horizontal inequity for the three health outcome variables ranges from -0.043 to -0.161 ; for the two utilization variables, the range is 0.080 to 0.121 . These indices indicate a relatively low degree of inequity in the Jamaican health system, but the concern is that they represent a deterioration of the situation three years prior, despite measures taken during this time ostensibly to address health equity. Of note is institution of the National Health Fund in October 2003 (3) and a program for ophthalmology care in Cuba in 2005 (21). In the socioeconomic context of Jamaica over the period 2004-2007, when unemployment and poverty rates remained in double digits, anemic economic growth was mixed with a period of recession, income disparity continued to widen, and government budgetary allocations remained strained because of excessive debt burden, these efforts may not have been enough to match a growing demand for health care services and less so to narrow the health equity gap. The narrow focus of these programs on specific diseases and benefits raises doubt about their potency to significantly affect health inequity without concomitant efforts to address the underlying structural problems that plague the health system. The hope is that abolition of all user fees at public health facilities in 2008 and introduction of the Government of Jamaica Health Card in 2009 (1) will contribute to a different set of results when data for later periods are analyzed.

By way of a decomposition of the CI, these results also found that the level of household welfare was the single most significant factor contributing to these inequalities. Rural location, unemployment, and health insurance coverage were other sources of inequities in health care utilization. The identification of these determinants provides a basis for designing appropriate strategies, policies, and programs to address these inequities.

While this study adds to the literature on health equity in LAC, it is not without noteworthy limitations. In particular, because of data constraints, the scope of this study was limited to the five health variables analyzed; quintile counts for other variables such as hospitalization and variables disaggregated by public-private sector were too few to give reliable results under the applied methodology. Apart from increasing the sample size of the JSLC, combining contiguous data sets is one way to overcome this limitation. Were it possible to include these variables, a more robust set of results could have been derived. It should also be noted that the applied methodology allows for comparisons of quantities of utilization with no account taken of differences in the quality of health services, which may also be relevant to inequities in health care. The methodology also does not evaluate the personal, psychosocial, or cultural aspects that could be determinants of health inequities.

The findings of this study point to the need for Jamaica to continue its commitment to a healthy and stable population (1) and to pursue strategies that will overcome the issues and challenges related to the promotion of health and health care access. The results found here suggest that strategies to consider include educational outreach targeted at specific groups to alter the perception of health, particularly given the growth in chronic and lifestyle diseases; financial support for food security for vulnerable groups; locating more health facilities in rural areas to correct the uneven distribution of such facilities across the country; and adequately resourcing and maintaining the health infrastructure in order to efficiently deliver quality health services. Jamaica has already embarked on some of these strategies, but they can be costly, with the potential for unintended consequences (22). International experiences and best practices must therefore be taken into account when implementing these strategies $(23,24)$, as Jamaican policy makers seek to find innovative ways to design and deliver these strategies in the most efficient and cost-effective manner. In this regardthat is, the inherent link between social and economic policy and the health of the population-the authors support the recommendation that health equity should play a central role in the design of all policy making at the national level (25). The authors also recommend that the methodology used in this study be applied as a matter of routine to the latest JSLC data as they become available and as such be taken as a tool for continuous monitoring and evaluation of the policies and programs put in place to enhance health equity in Jamaica.

\section{Conclusion}

This study found pro-poor inequity in health status and outcomes and prorich inequity in health care utilization in Jamaica for the years 2004 and 2007, a pattern that was reported before the turn of the century. This finding indicates persistence in the paradox that the population group that needs health care most is accessing it least. The results also showed that this disparity increased over the period 2004-2007 in spite of measures taken ostensibly to address this persistent reality. Other than income disparity, the identified major sources of inequities in health care utilization were rural location, unemployment, and health insurance coverage.

Funding. This study was funded by the Equity in Health Systems in Latin America and the Caribbean (EquiLAC) Project of the Pan American Health Organization.

Conflict of interest. None. 


\section{REFERENCES}

1. Planning Institute of Jamaica. Vision 2030 Jamaica National Development Plan. Kingston: PIOJ; 2009.

2. National Health Fund of Jamaica. Kingston: Government of Jamaica; 2009. Available from: http://www.nhf.org.jm/ Accessed 2 June 2012.

3. Patterson C. Jamaica has proud track record in healthcare delivery. Jamaica Information Service News 2012. June 1.

4. Myers J Jr. New NIS rate now in effect. Jamaica Gleaner 2003. October 3.

5. Francis P. Medics warn of hospital chaos: say free health care will burden system. Jamaica Gleaner 2008. March 5.

6. Bustamante Hospital avalanche: user-fee abolition burdens hospital staff, resources. Jamaica Gleaner 2008. March 31.

7. Theodore K, Lafoucade A, Stoddard D, Thomas W, Yearwood A. Health system inequities and poverty in Jamaica. In: Pan American Health Organization, ed. Investment in health: social and economic returns. Washington, D.C.: PAHO; 2001. Pp. 189-202.

8. van Doorslaer E, Wagstaff A. Inequity in the delivery of health care: methods and results for Jamaica. In: Pan American Health Organization, ed. Investment in health: social and economic returns. Washington, D.C.: PAHO; 2001. Pp. 233-44.

9. Pan American Health Organization. Investment in health: social and economic returns. Washington, D.C.: PAHO; 2001.

10. Dachs JN, Ferrer M, Florez CE, Barros AJ, Narváez R, Valdivia M. Inequalities in health in Latin America and the Caribbean: de- scriptive and exploratory results for selfreported health problems and health care in twelve countries. Rev Panam Salud Publica. 2002;11(5-6):335-55.

11. van Doorslaer E, Masseria C, Koolman X, OECD Health Equity Research Group. Inequalities in access to medical care by income in developed countries. CMAJ. 2006;174(2):177-83.

12. Mills A, Ataguba JE, Akazili J, Borghi J, Garshong B, Makawia S, et al. Equity in financing and use of health care in Ghana, South Africa, and Tanzania: implications for paths to universal coverage. Lancet. 2012;380(9837) 126-33.

13. Mackenbach JP. The persistence of health inequalities in modern welfare states: the explanation of a paradox. Soc Sci Med. 2012;75(4):761-9.

14. O'Donnell O, van Doorslaer E, Wagstaff A, Lindelow M. Analyzing health equity using household survey data: a guide to techniques and their implementation. Washington, D.C.: World Bank; 2008.

15. Wagstaff A, van Doorslaer E, Watanabe N. On decomposing the causes of health sector inequalities, with an application to malnutrition inequalities in Vietnam. J Econom. 2003;112(1):207-23

16. Almeida G, Sarti FM. Measuring evolution of income-related inequalities in health and health care utilization in selected Latin American and Caribbean countries. Rev Panam Salud Publica. 2013;33(2):83-9.

17. Planning Institute of Jamaica, Statistical Institute of Jamaica. Jamaica Survey of Living
Conditions data sets 2004, 2007. Kingston: PIOJ, STATIN; 2006, 2009.

18. Derek Gordon Databank. Mona: University of the West Indies SALISES; 2003. Available from: http://salises.mona.uwi.edu/ databank/databank.html Accessed 29 May 2011.

19. World Bank Development Research Group Human Resources. Jamaica Survey of Living Conditions (JSLC) 1988-2000 basic information. Washington, D.C.: World Bank; 2002.

20. World Health Organization. National health accounts. Geneva: WHO; 2012. Available from: http://www.who.int/nha/en/ Accessed 25 April 2012

21. Gorry C. Sight for sore eyes: Cuba's vision restoration program. MEDICC Rev. 2008;10(2):49-51

22. Hall A. Hefty price for free health care. Jamaica Gleaner 2010. April 10.

23. McPake B, Brikci N, Cometto G, Schmidt A, Araujo E. Removing user fees: learning from international experience to support the process. Health Policy Plan. 2011;26(Suppl 2):ii104-17.

24. Meefssen B, Gilson L, Tibouti A. User fee removal in the health sector in low-income countries: sharing knowledge to support managed implementation. Health Policy Plan. 2011;26(Suppl 2):ii1-4.

25. Marmot MG. Policy making with health equity at its heart. JAMA. 2012;307(19):2033-4.

Manuscript received on 7 March 2012. Revised version accepted for publication on 16 January 2013.
RESUMEN

Medición e interpretación de las desigualdades en la salud y la atención sanitaria en Jamaica, 2004 y 2007

Palabras clave
Objetivo. Medir y explicar las desigualdades y las inequidades del sistema de salud de Jamaica a fin de obtener evidencia que apoye el desarrollo, el seguimiento y la evaluación de las políticas de salud.

Métodos. Se usaron los datos de la Encuesta sobre Condición de Vida en Jamaica de 2004 y 2007, representativas del país. Se midieron las desigualdades relacionadas con los ingresos mediante curvas e índices de concentración de tres variables de resultados en salud (probabilidad de enfermedad o lesión, duración de la última enfermedad y autoevaluación del estado de salud) y dos variables de utilización de servicios (probabilidad de recibir atención sanitaria y número de consultas sanitarias). Se utilizaron sus contrapartes estandarizadas para medir las inequidades. Con la descomposición del índice de concentración se explica la contribución de los factores socioeconómicos y demográficos a las desigualdades.

Resultados. La probabilidad de enfermar y la duración de la enfermedad se concentraron en la población de menores ingresos, con una clara desigualdad a favor de las personas de mayores ingresos en la utilización de los servicios de salud. Estas desigualdades e inequidades crecieron en el período 2004-2007. El nivel del bienestar doméstico fue el factor único que más contribuyó a estas desigualdades; otros factores que contribuyeron de manera significativa para los resultados en salud fueron el desempleo y la ubicación rural y, para la utilización de los servicios, tener seguro de salud.

Conclusiones. A pesar de las medidas tomadas en Jamaica relacionadas con la equidad en la salud, las desigualdades en los resultados en salud y en la atención sanitaria relacionadas con los ingresos han aumentado y el grupo de población que más necesita los servicios de salud es el que menos los usa. El país requiere programas más innovadores orientados a mejorar la equidad en salud.

Equidad en salud; equidad en el acceso; sistemas de salud; economía de la salud; política de salud; Jamaica. 
REVISTA

PANAMERICANA

DE SALUD PÚBLICA
PAN AMERICAN

JOURNAL OF

PUBLIC HEALTH

Material suplementario / Supplementary material / Material supplementar

Supplementary material to:

Barraza-Lloréns M, Panopoulou G, Díaz BY. Income-related inequalities and inequities in health and health care utilization in Mexico, 2000-2006. Rev Panam Salud Publica. 2013;33(2):122-30.

This material formed part of the original submission and has been peer reviewed. We post it as supplied by the authors. 


\section{Annex. Concentration curves}

Figure 1

Health outcome: Chronic illness (any) Ranking variable: Income

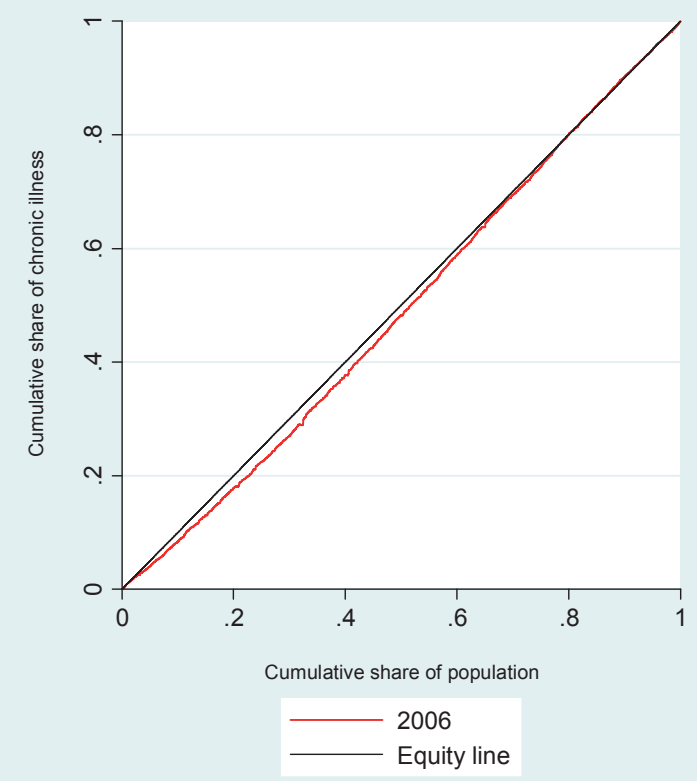

Figure 2

Health outcome: Chronic illness (any)

Ranking variable: Wealth index

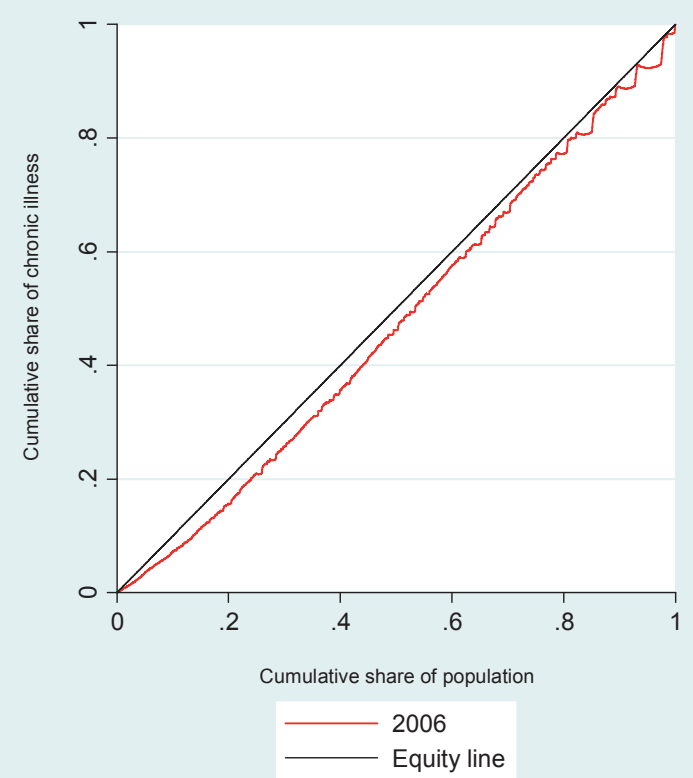


Figure 3

Health outcome: Physical limitation (any)

Ranking variable: Income

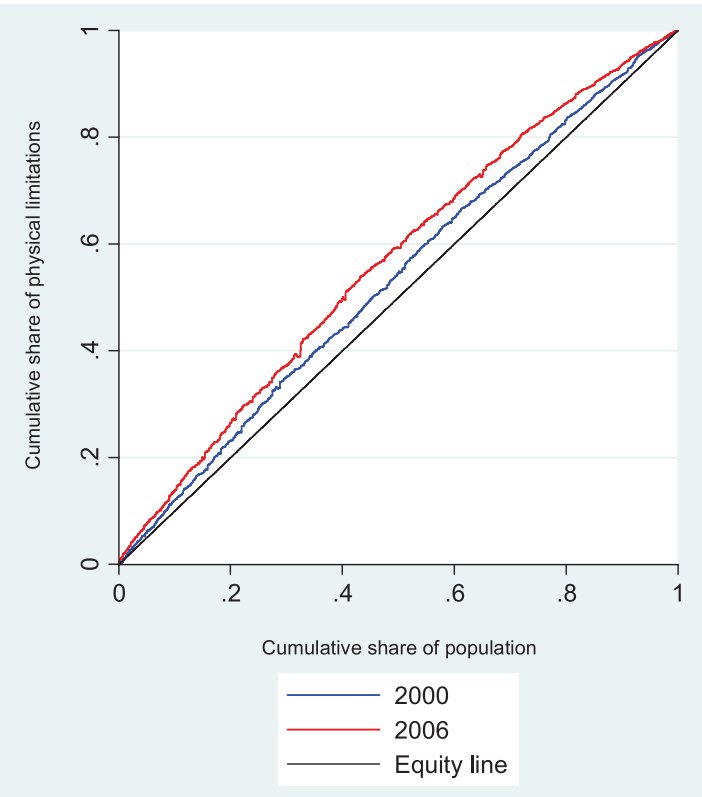

Figure 4

Health outcome: Physical limitation (any)

Ranking variable: Wealth index

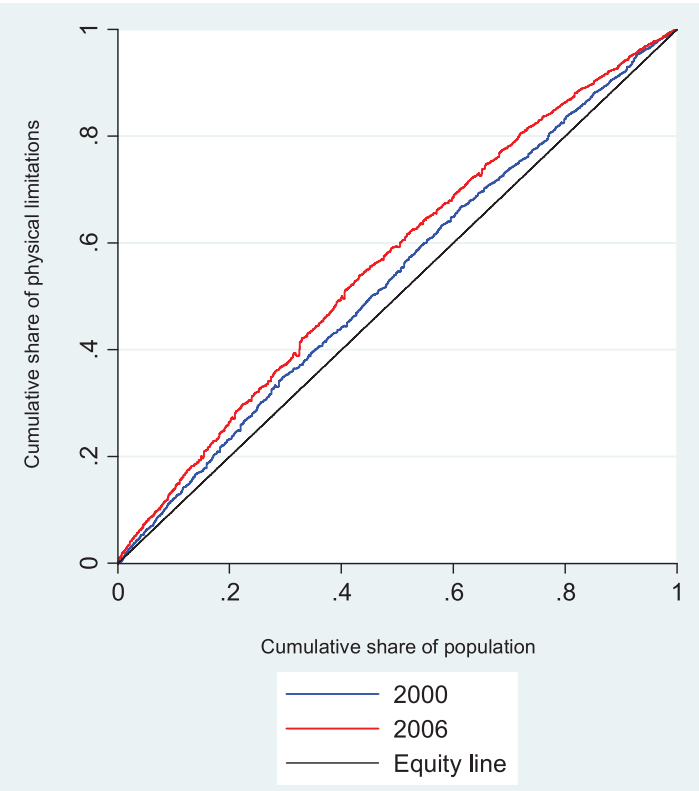


Figure 5

Health outcome: Self-assessed health status (less than good) Ranking variable: Income

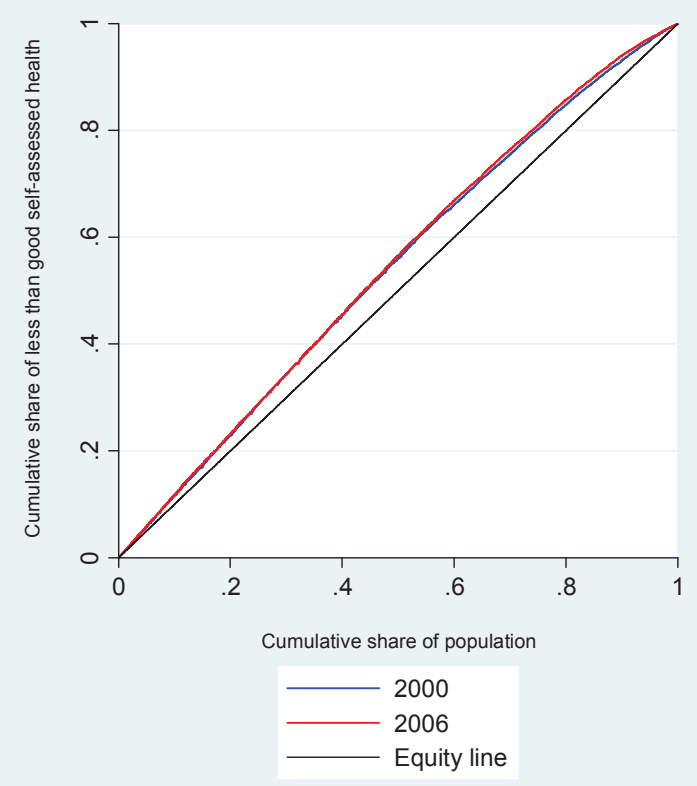

Figure 6

Health outcome: Self-assessed health status (less than good) Ranking variable: Wealth index

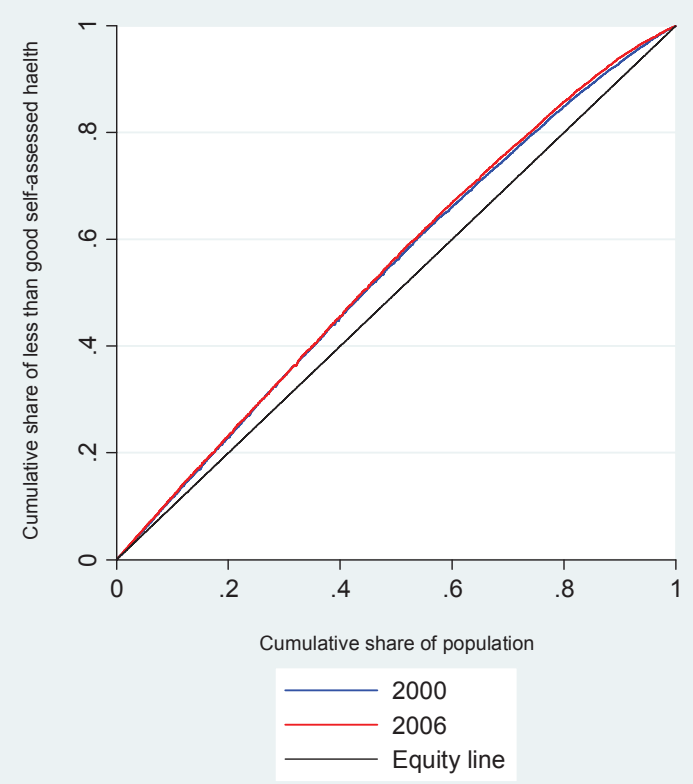


Figure 7

Health care utilization: Dental care Ranking variable: Income

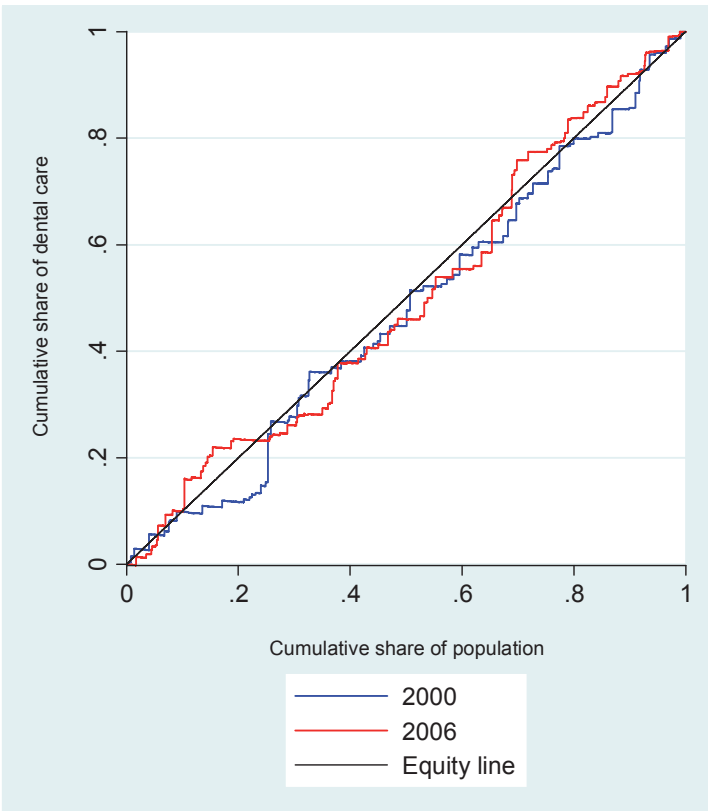

Figure 8

Health care utilization: Dental care

Ranking variable: Wealth index

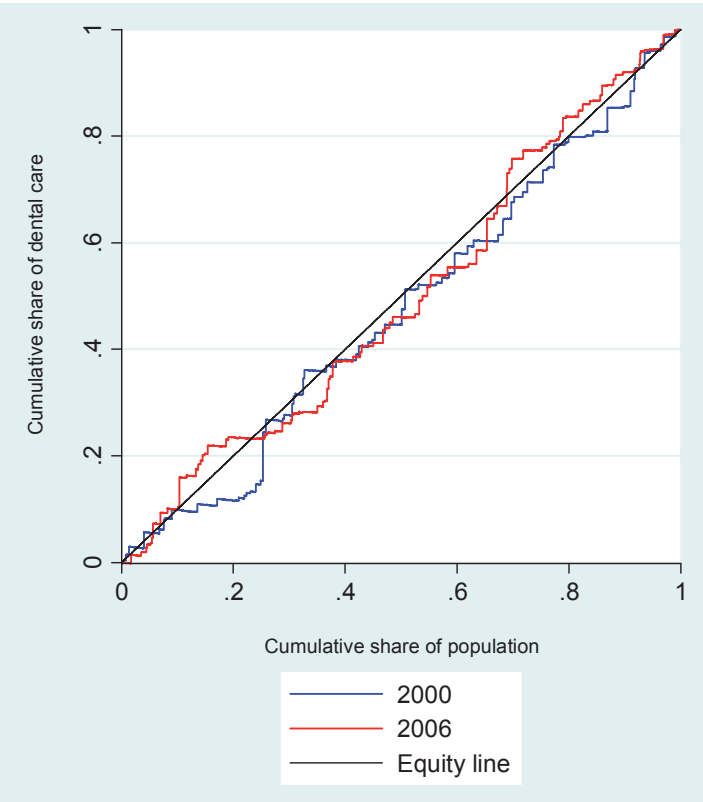


Figure 9

Health care utilization: Hospitalization

Ranking variable: Income

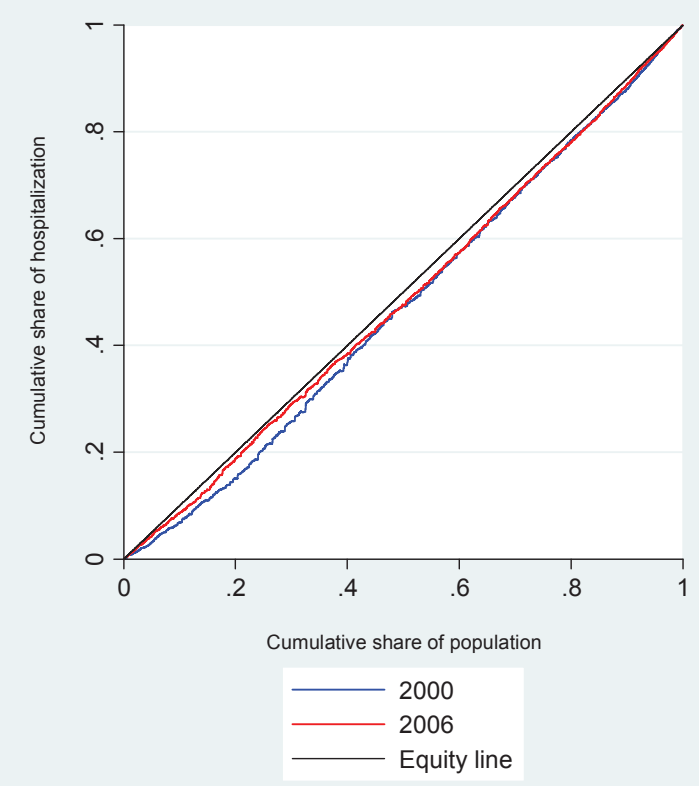

Figure 10

Health care utilization: Hospitalization

Ranking variable: Wealth index

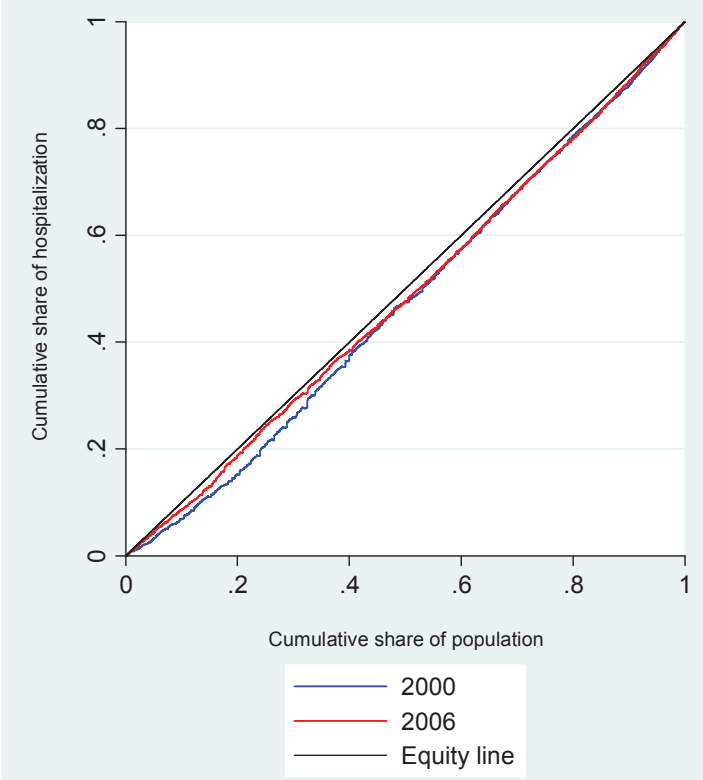


Figure 11

Health care utilization: Inpatient days

Ranking variable: Income

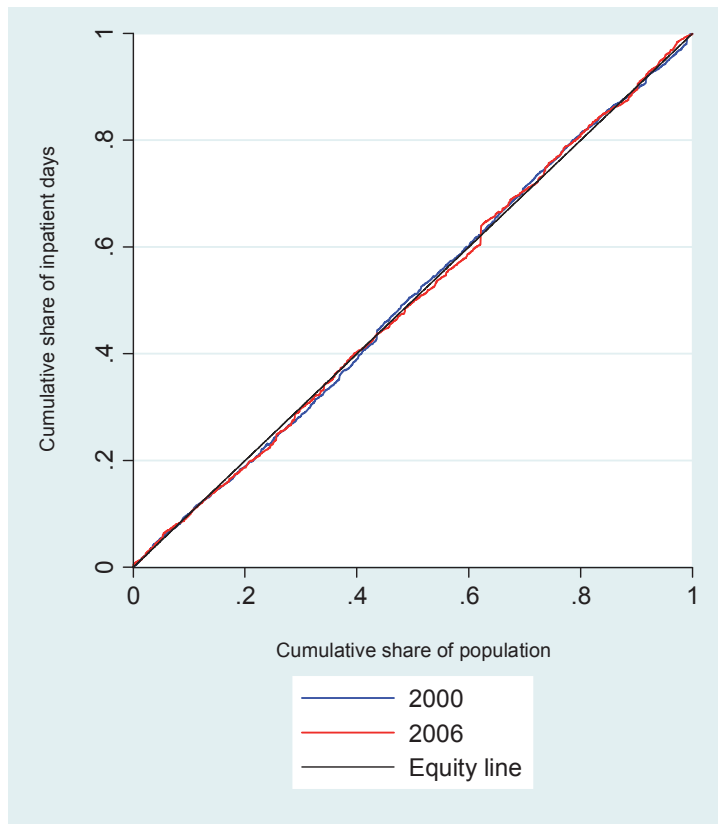

Figure 12

Health care utilization: Inpatient days

Ranking variable: Wealth index

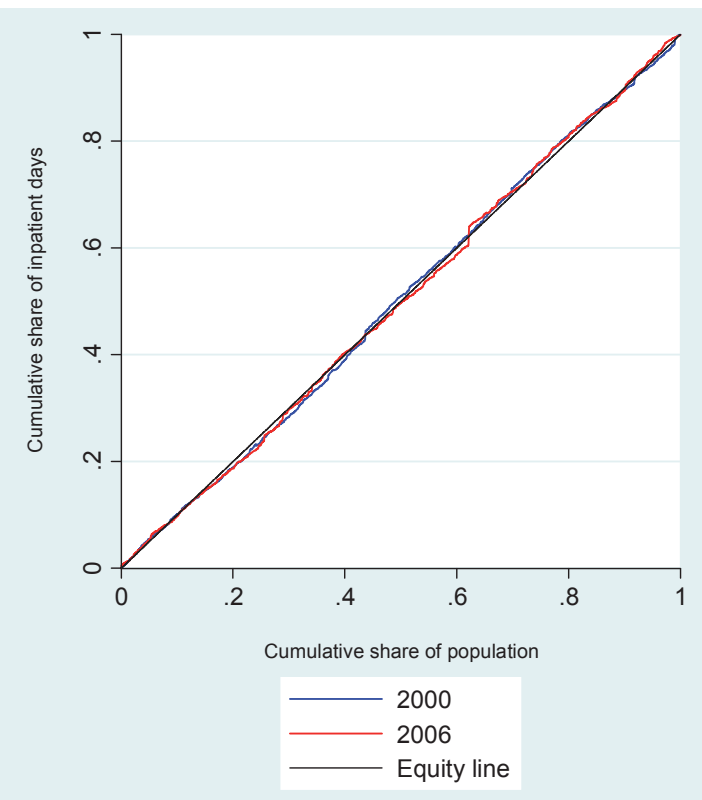


Figure 13. Health care utilization: Curative visits Ranking variable: Income

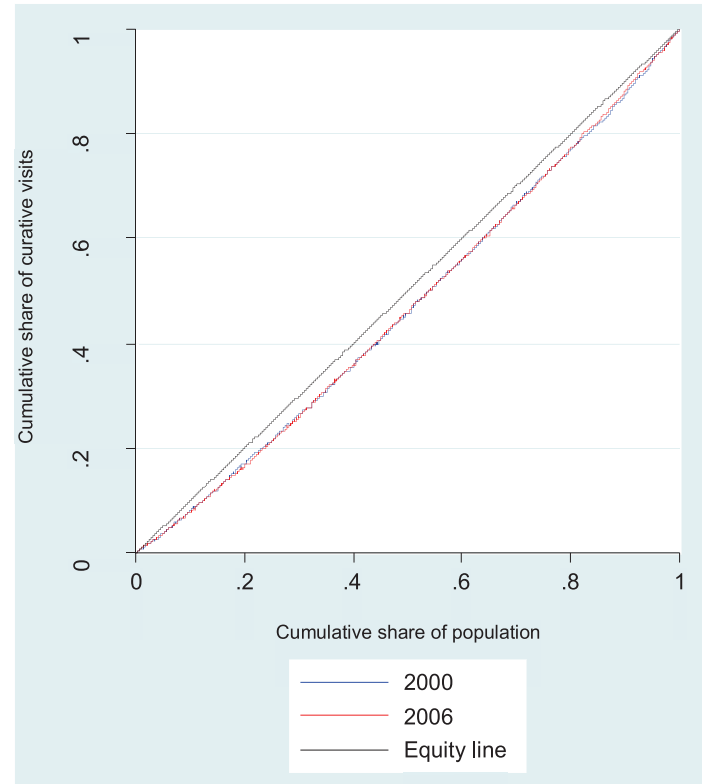

Figure 14. Health care utilization: Curative visits Ranking variable: Wealth index

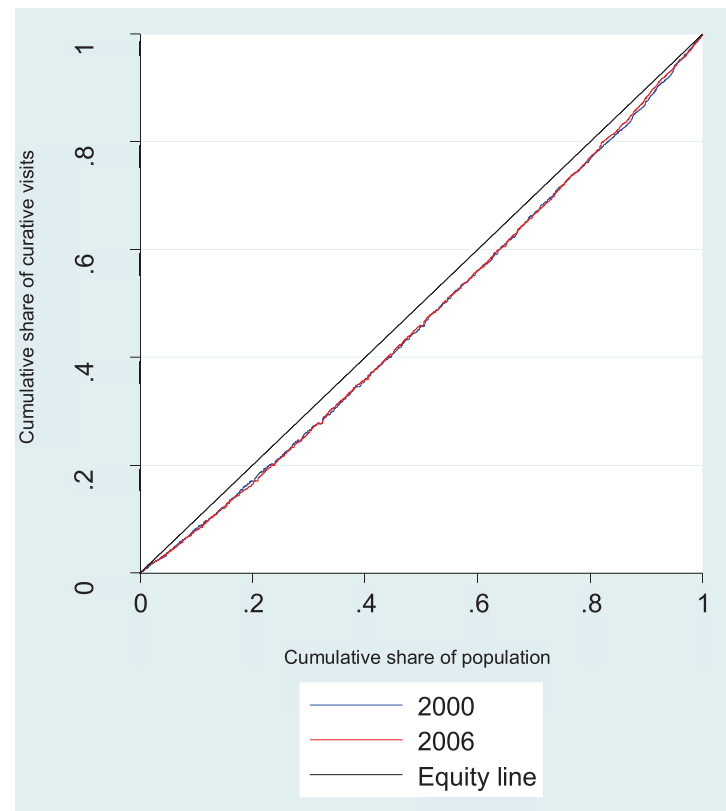


Figure 15

Health care utilization: Preventive care Ranking variable: Income

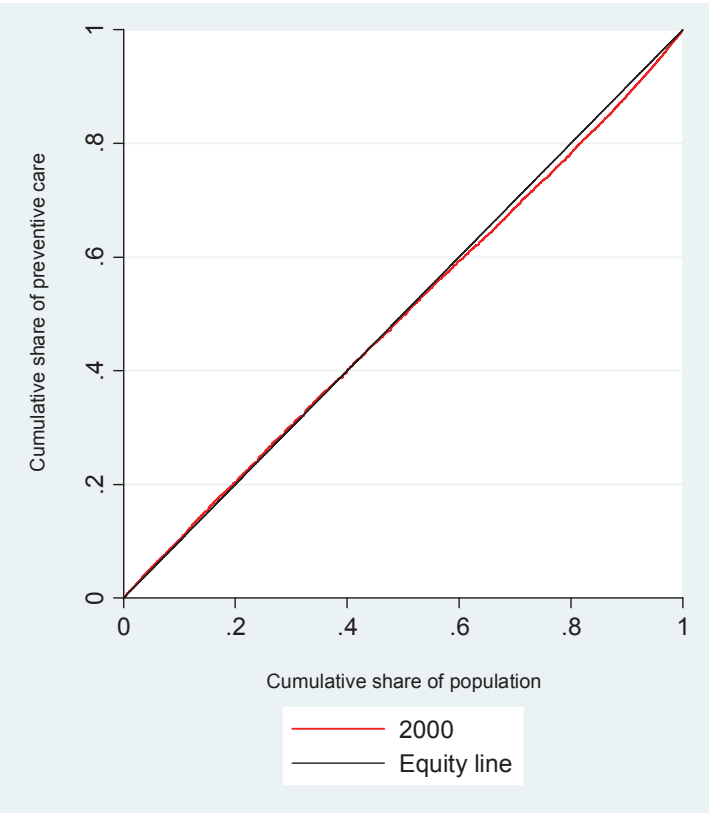

Figure 16

Health care utilization: Preventive care Ranking variable: Wealth index

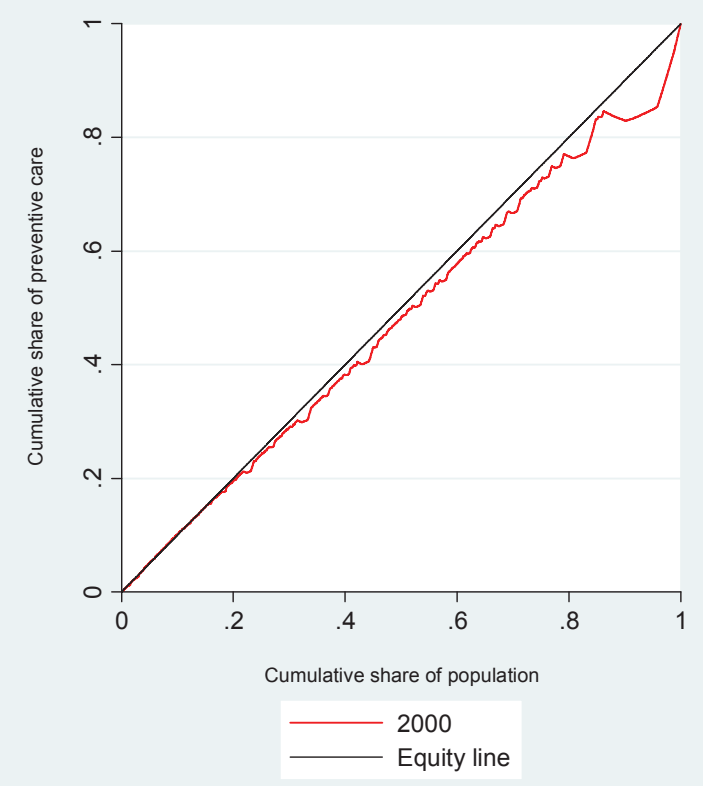

